T R I B U N A

\title{
Sinopsis del Convenio Hispano-Marroquí de Seguridad Social: desempleo, no contributivas, viudedad y poligamia
}

\section{SYNOPSIS OF THE SPANISH-MOROCCAN SOCIAL SECURITY AGREEMENT: UNEMPLOYMENT, FAMILY BENEFITS, WIDOWHOOD AND POLYGAMY}

\author{
Cristina Sánchez-Rodas Navarro \\ Catedrática de Derecho del Trabajo y de la Seguridad Social \\ Universidad de Sevilla \\ csrodas@us.es@0000-0001-9780-7860
}

Recibido: 17.06.2021 | Aceptado: 17.06.2021

\section{SUMARIO}

I. INTRODUCCIÓN

II.PRESTACIONES EXCLUIDAS DE LAS COORDINACIÓN

A. Desempleo

B. Prestaciones no contributivas de seguridad social

III. PENSIÓN DE VIUDEDAD Y POLIGAMIA

\section{INTRODUCCIÓN}

El Convenio Hispano-Marroquí entró en vigor el 1 de octubre de 1982, siendo el más antiguo de los convenios bilaterales que España tiene actualmente en vigor. Dicho Convenio es aplicable al Régimen General de la Seguridad Social y a los siguientes regímenes especiales: Trabajadores del Mar, Trabajadores por Cuenta Propia o Autónomos, Minería del Carbón y Seguro Escolar. No están incluidos los Regímenes Especiales de Funcionarios.

El Convenio Hispano-Marroquí sólo coordina prestaciones económicas contributivas de Seguridad Social. 


\section{PRESTACIONES EXCLUIDAS DE LAS COORDINACIÓN}

\section{A. Desempleo}

A diferencia del Convenio Portugués-Marroquí que sí incluye dentro de su ámbito de aplicación material a las prestaciones por desempleo, el Convenio Hispano-Marroquí no las menciona por lo que hay que concluir que quedan excluidas tanto las contributivas como asistenciales. Tampoco el Acuerdo Euromediterráneo es aplicable a estas prestaciones. Entonces, ¿por qué cotizan por desempleo los trabajadores transfronterizos? Estos últimos son los que han sido autorizados "para desarrollar actividades lucrativas, laborales o profesionales por cuenta propia o ajena en las zonas fronterizas del territorio español, residiendo en la zona fronteriza de un Estado limítrofe al que regrese diariamente" -artículo 182 Real Decreto 557/2011-. Consecuencia de residir en un Tercer Estado debiera ser la exclusión de los trabajadores transfronterizos de la obligación de cotizar por desempleo, tal y como establecía la Disposición Adicional $13^{a}$ del derogado Real Decreto 2393/2004. Exclusión que se justifica por el hecho de que, conforme a la legislación española, es causa de extinción del derecho a la prestación por desempleo el traslado de la residencia al extranjero. Y en caso de los trabajadores marroquíes transfronterizos estos residen, por definición legal, en el extranjero. A la vista de las consideraciones anteriores no se alcanza a comprender cómo el vigente Reglamento de Extranjería no excluye, como excluía el anterior Reglamento de Extranjería, a los trabajadores transfronterizos de la obligación de cotizar por desempleo.

\section{B. Prestaciones no contributivas de Seguridad Social}

Conforme al artículo 3 del Convenio Hispano-Marroquí para que el Convenio resulte aplicable a disposiciones "sobre una nueva rama de la Seguridad Social" las dos partes contratantes han de convenir en ello", con mayor motivo se precisa un acuerdo expreso entre ambos Estados para incluir en el ámbito de aplicación material del convenio un nuevo nivel de Seguridad Social inexistente cuando el Convenio se negoció. Y, hasta la fecha, no consta acuerdo alguno entre ambos países respecto al nivel no contributivo de Seguridad Social español. Como el Tribunal Supremo reconoció en su sentencia de 1 de abril de 1998 (recurso 588/1997) para que una nueva rama de la Seguridad Social pueda incluirse en el Convenio Hispano-Marroquí es necesario un pacto bilateral expreso:"que la protección otorgada por las denominadas prestaciones no contributivas de la Seguridad Social constituye una nueva rama, debe deducirse con claridad, no tanto de la naturaleza de las propias prestaciones y contingencias protegidas, como de su fuente de financiación y, sobre todo, de su desvinculación como relación protectora, de la relación de prestación de servicios por cuenta ajena, en abierta diferenciación con el ámbito protector contributivo". 
A pesar de ello, al amparo de la Circular del INSS 4/2006 se abonan prestaciones familiares no contributivas aun cuando los hijos o acogidos no residan en territorio nacional. A mayor abundamiento, la citada Circular prevé también en el apartado 14.2.6 que "podrán ser beneficiarios de la prestación los trabajadores transfronterizos que residan en la zona fronteriza de Marruecos, respecto de los hijos que estén a su cargo y que residan también en Marruecos". Tal previsión carece de cualquier fundamento legal ya que ni los transfronterizos, ni sus hijos o menores a cargos, residen en España por lo que no cumplen los requisitos del TRLGSS. Ni el Convenio-Hispano marroquí, ni el Acuerdo Administrativo, reconocen derecho a prestaciones familiares para los trabajadores transfronterizos. Tampoco el Reglamento 1231/2010 legitima el abono de prestaciones familiares fuera del territorio de la Unión Europea.

\section{PENSIÓN DE VIUDEDAD Y POLIGAMIA}

Ni la legislación española ni la de ningún Estado de la Unión Europea permite la celebración de matrimonios polígamos. En palabras del Tribunal Supremo "la poligamia no es simplemente algo contrario a la legislación española, sino algo que repugna al orden público español, que constituye siempre un límite infranqueable a la eficacia del Derecho extranjero". Los tribunales españoles no han mantenido una interpretación uniforme sobre la pensión de viudedad en caso de poligamia, siendo a estos efectos clave que existiera Convenio bilateral que reconociera el derecho a pensión, o no. Respecto a Marruecos los pronunciamientos han sido favorables, puesto que el Convenio bilateral de Seguridad Social en su artículo 23 prevé que la pensión de viudedad causada por un trabajador marroquí será distribuida, en su caso, por partes iguales y definitivamente entre quienes resulten ser, conforme a la legislación marroquí, beneficiarias de dicha prestación.

Cuando parecía pacífica la interpretación del artículo 23 del Convenio Hispano-Marroquí en España, la STS del Tribunal Supremo de 24 de enero de 2018 (nº recurso 98/2017) ha dado un "giro de tuerca" al reconocer pensión de viudedad a la segunda esposa de un súbdito marroquí incluido en el Régimen de Clases Pasivas del Estado. Nada habría que objetar al fallo si no fuera porque la Sala de lo Contencioso-administrativo no se limita a interpretar y aplicar el Convenio, sino que procede a ampliar el ámbito de subjetivo de aplicación del mismo, y todo ello al margen de los mecanismos que el propio Convenio Hispano-Marroquí prevé para una medida de tal naturaleza.

En efecto, la piedra angular sobre la que la STS de 24 de enero 2018 pasa de "puntillas" -no así el acertadísimo voto particular- es que el sujeto causante no estaba protegido por ninguno de los regímenes de Seguridad Social coordinados por el Convenio Hispano-Marroquí. Resulta obvio que el paso previo y necesario antes de pronunciarse sobre si una persona tiene derecho a una prestación coordinada por el Convenio es comprobar si a esa persona le es aplicable el Convenio. Porque si no está incluida dentro de su ámbito de aplicación personal, huelga todo debate jurídico. Y sucede que los Regímenes Especiales de Funcionarios no están incluidos 
en el Convenio Hispano-Marroquí. Por tanto, cuando a la primera esposa del sujeto causante polígamo se le reconoce pensión española de viudedad, ésta se le reconoce en base exclusivamente a la legislación de Clases Pasivas del Estado, no en virtud del Convenio Hispano-Marroquí y nada hay que objetar al respecto.

En cambio, la pretensión de la segunda esposa sólo puede pivotar sobre el artículo 23 del Convenio Hispano-Marroquí. Pero, al estar excluidos los Regímenes Especiales de Funcionarios del Convenio Hispano-Marroquí, no es aplicable el Convenio ni al sujeto causante ni a los miembros de su familia.

La exclusión de los Regímenes Especiales de Funcionarios Públicos del Convenio Hispano-Marroquí no es un "olvido" sino una expresa opción política del Estado español. A mayor abundamiento, al describir su ámbito de aplicación los Convenios bilaterales de Seguridad Social españoles especifican que se aplican a trabajadores por cuenta ajena y por cuenta propia. Y solo si un Convenio es aplicable a Clases Pasivas así se indica expresamente, tal y como hace el Convenio de Seguridad Social Hispano-Japonés (2008). Sin olvidar que los regímenes especiales de funcionarios también están excluidos del Convenio Multilateral Iberoamericano de Seguridad Social.

A la vista de las consideraciones expuestas se concluye que la sentencia de la Sala de lo Contencioso-Administrativo del Tribunal Supremo 24.1.2018 ( $n^{\circ}$ recurso 98/2017) no aplicó el Convenio Hispano-Marroquí (porque no está incluido dentro de su ámbito de aplicación personal el sujeto causante polígamo) ni la normativa sobre Clases Pasivas (que prohíbe el reparto de pensiones de viudedad en caso de matrimonios polígamos, contrario al orden público). Tampoco se fundamenta la sentencia específicamente en ningún Tratado internacional ratificado por España. Y por lo que respecta al Convenio Europeo de Derechos Humanos es significativo que el Tribunal Europeo de Derechos Humanos no haya dictado hasta la fecha ninguna sentencia que considere infringido el CEDH si se deniega pensión de viudedad a más de un cónyuge supérstite en caso de poligamia.

A pesar de lo expuesto, la STS de 17 de diciembre de 2019 (recurso núm. 2679/2017) respecto a un supuesto de poligamia de un sujeto causante beneficiario de una pensión de Clases Pasivas concluye que "debemos llegar a la misma decisión que alcanzamos en aquella sentencia de 24 de enero de 2018, pues las razones jurídicas expuestas en el presente recurso no difieren, en lo esencial, de las que entonces valoramos". Exactamente las mismas críticas merece esta sentencia que la precedente.. 